\title{
RaÍCES EN EL AIRE. EsPacios SOCIALES \\ RURALES Y MOVILIDADES EN LA REGIÓN \\ PAMPEANA BONAERENSE CONTEMPORÁNEA
}

Roots in the Air. Rural Social Spaces and Mobilities in Contemporary Buenos

Aires Pampas Region.

\author{
Verónica Hendel \\ vero_hendel@yahoo.com \\ CONICET-UNLU-UBA
}

RESUMEN: Este trabajo pretende analizar algunos de los modos en que se produce y reproduce socialmente la vida y se construyen cotidianeidades en el ámbito rural pampeano bonaerense de la Argentina, en el marco de las tendencias homogeneizantes contemporáneas del capital y las políticas neoliberales. Modos que inciden sobre los espacios sociales rurales, transformándolos, resignificándolos y construyendo nuevos diálogos entre lo urbano y lo rural. El avance de nuevas maquinarias y tecnologías que prescinden, cada vez en mayor medida, de los trabajadores y operarios rurales y desplazan a los pequeños productores familiares, por un lado, y una suerte de «vuelta al campo» protagonizada por sectores urbanos de altos ingresos, que pretende reconstruir un pasado rural que nunca existió en forma de casas quinta de fin de semana, barrios privados y clubes de chacra, se conjugan dando lugar a movilidades que inciden de modos diversos sobre los espacios sociales rurales pampeanos. Aquí analizaremos esta problemática poniéndola en diálogo con las nociones de «arraigo» y «desarraigo», y dando cuenta de ciertos rasgos centrales de las reconfiguraciones materiales, políticas, sociales, culturales y simbólicas que han atravesado, y están atravesando, los espacios rurales en la región pampeana bonaerense.

Palabras clave: espacio social rural, movilidades, región pampeana bonaerense, nueva ruralidad, arraigo. 
ABSTRACT: This paper analyzes some of the ways in which life is socially produced and reproduced in the Buenos Aires Pampas region, in the context of contemporary homogenizing tendencies of capital and neoliberal policies. Rural social spaces are affected by these processes, which transform and resignify them, and build new dialogues between the urban and the rural. Advances in new machinery and technologies that increasingly dispense with rural workers and displace small family producers, on the one hand, and a sort of "return to the countryside" led by high-income urban sectors, which seeks to reconstruct a fictitious rural past in the form of weekend houses, private neighborhoods and country clubs, combine to give rise to mobilities that affect the rural social spaces of the Pampas in different ways. In this paper we analyze this problem by contrasting it with the notions of "rootedness" and "uprooting", and describe some central features of the material, political, social, cultural and symbolic reconfigurations that rural spaces in the Buenos Aires Pampas region have experienced, and continue to experience.

Keywords: rural social space, mobilities, Buenos Aires Pampas region, new rurality, root.

\section{Introducción}

A partir de ahí, uno si visualiza el pueblo, eh, se fueron dando muchas modificaciones en el contexto productivo, los tambos empezaron a desaparecer conjuntamente con la desaparición del tren en el año 96 [...]. Una muestra evidente está en la escuela, hoy el máximo de alumnos ronda entre los 10, 14 alumnos en total, cuando, bueno, antes éramos 40,50, ehh, y familias muy nómades, o sea, van buscando la mejor condición de empleo, algunos están 2 o 3 meses y se van, vienen otras familias, 2 o 3 meses y se van, se nota como que, eso también hace que la gente no se apropie de la localidad por ejemplo. (San Andrés de Giles, 2013)

Entonces llevó a que pasara, a que pasara todo esto. Y en el campo, ibas al campo, el mismo camino donde antes habíamos 14 familias... no hay nada, taperas. Taperas o nada, planicie, se borró el monte, con la retroexcavadora borraron casas, borraron todo. (San Andrés de Giles, 2013) 
$\mathrm{E}$ l campo y la ciudad son realidades históricas variables tanto en sí mismas como en las relaciones que mantienen. Sin embargo, es posible constatar que, a pesar de las transformaciones sociales y espaciales ocurridas en las últimas décadas, «las ideas y las imágenes del campo y la ciudad conservan una gran intensidad» (Williams, 2001: 357). Y esta persistencia, que describe Raymond Williams pensando en otros espacios y temporalidades, constituye un aspecto central del análisis que venimos realizando a lo largo de diversos escritos (Hendel, 2014; 2015; 2018) y que aquí retomaremos atendiendo a la pregunta por algunos de los modos en que se produce y reproduce socialmente la vida y se construyen cotidianeidades en el ámbito rural pampeano bonaerense de la Argentina, en el marco de las tendencias homogeneizantes contemporáneas del capital y las políticas neoliberales. Modos que inciden sobre los espacios sociales rurales ${ }^{1}$, transformándolos, resignificándolos y construyendo nuevos diálogos entre lo urbano y lo rural.

La región pampeana argentina, sinónimo por excelencia del ámbito rural en la región, ha atravesado a lo largo de las últimas décadas una transformación productiva sin igual. Impulsada por el aumento del precio internacional de la soja a finales del siglo XX, a comienzos del siglo XXI dicha «revolución» ha dado lugar a profundos cambios en los procesos productivos (introducción de la siembra directa, tecnologías de precisión, uso de semillas transgénicas, etc.) y en los procesos de gestión (nuevas tecnologías de la comunicación e información, profesionalización de la administración, entre otras). En este contexto, cabe señalar que en vastas zonas rurales del interior bonaerense se plantea un círculo vicioso que incluye una estructura económica fuertemente asociada a la actividad agropecuaria y ausencia de atractivos para la radicación de nuevos emprendimientos y diversificación productiva, lo cual redunda en falta de oportunidades de empleo y expulsión (Gorenstein et al., 2007).

1. El concepto de espacio social rural que aquí trabajaremos retoma la obra de Elisa Cragnolino, en su apropiación y recreación de la obra de Pierre Bourdieu, y «hace hincapié en la diferencia y la desigualdad y, por lo tanto, la cuestión del poder e introduce la dimensión histórica como central» (Cragnolino, 2011: 5) 
Este trabajo retoma aspectos centrales de nuestra investigación doctoral ${ }^{2}$ y se encuentra íntimamente ligado a la trama de saberes, experiencias y prácticas que hemos podido reconstruir a partir del trabajo de campo desarrollado entre los años 2007 y 2013 en un distrito de la provincia de Buenos Aires, el partido de San Andrés de Giles ${ }^{3}$ y, específicamente, en una escuela rural técnica de alternancia, el Centro Educativo para la Producción Total $\mathrm{N}^{\circ} 2 .^{4}$ Esta mención tan puntual radica en el hecho de que fue a partir del vínculo con esta escuela que pudimos comenzar a relacionarnos con un conjunto diverso y heterogéneo de instituciones y actores sociales locales (desde la Sociedad Rural distrital hasta los pequeños productores devenidos trabajadores rurales precarizados o caseros de casas de fin de semana).

En tiempos en que el ámbito rural pampeano de la Argentina ${ }^{5}$ atraviesa profundos cambios, las fronteras entre las nociones de campo y ciudad, que

2. En el marco de la tesis doctoral, «Síntomas de una ausencia. Acerca de la experiencia contemporánea de lo rural en la región pampeana bonaerense (2007-2013)» (2015), nos dedicamos al análisis de las transformaciones recientes en el ámbito rural pampeano bonaerense, investigación que prestó especial atención a la movilidad rural y rural-urbana de jóvenes y adultos vinculados a espacios educativos y productivos del partido de San Andrés de Giles. A lo largo de los últimos años nos hemos abocado a la reconstrucción y análisis de las trayectorias socioeducativas de jóvenes y adultos que han migrado recientemente desde zonas rurales a zonas urbanas y que residen, actualmente, en el barrio conocido popularmente como «Fuerte Apache», en el conurbano bonaerense.

3. El partido de San Andrés de Giles, por su parte, se encuentra ubicado en el noreste de la provincia de Buenos Aires y al noroeste del Área Metropolitana de Buenos Aires (AMBA). A una distancia aproximada de unos $110 \mathrm{~km}$ de la Ciudad de Buenos Aires, abarca una superficie de 1135 kilómetros cuadrados. Posee una posición equidistante entre el principal aglomerado urbano del país y la zona de mayor productividad agraria, también de todo el país. Esa particularidad sitúa al partido en un ámbito de confluencia de fuerzas, la expansión urbana que se acerca desde el este y la expansión agraria que avanza desde el noroeste. Sin embargo, el paisaje que se configura es netamente rural y agropecuario, lo que no significa que las fuerzas urbanizadoras no estén latentes o que no compitan con las rurales.

4. El proyecto de los Centros Educativos para la Producción Total (CEPT) constituye una experiencia reciente en la región pampeana. Creado en el contexto del retorno a la democracia, y a partir de una adaptación de la alternancia a la problemática rural bonaerense, el proyecto CEPT ha logrado sobrevivir a las profundas crisis y transformaciones que han caracterizado a la región durante las últimas dos décadas. Habiendo partido de las premisas de que la vida enseña y educa, y de que el trabajo y la producción constituyen espacios privilegiados de formación, a lo largo de los últimos años, los protagonistas del proyecto CEPT se han encontrado, y se encuentran, ante el desafío de repensar los fundamentos del mismo.

5. Se trata de un área comprendida por las provincias de Buenos Aires, Córdoba, Entre Ríos, La Pampa y Santa Fe de la República Argentina. 
se encuentran en crisis desde la década de 1960 (Soja, 2008; Hendel, 2015), se tornan cada vez más difusas, se redefinen y, en ciertos casos, amalgaman dando forma a configuraciones singulares de los espacios sociales rurales. En el marco de esta crisis de larga duración, y en el contexto específico de nuestro trabajo de campo, la noción de «movilidades» ha emergido como un concepto relevante para pensar algunas de las características actuales de la vida en los espacios sociales rurales (Hendel, 2016). ${ }^{6}$ Y se trata de una noción construida a la luz del análisis de los relatos de los sujetos sociales rurales junto a quienes transitamos el recorrido investigativo que aquí retomamos? Movilidades que se encuentran atravesadas por relaciones de poder, pujas, tensiones y luchas. Cabe señalar que esta apelación a los relatos individuales no implica la adscripción a una concepción de «sociedad» entendida como compuesta de individuos, sino que, retomando nuevamente la obra de Cragnolino, «remite a posiciones sociales que son independientes de la voluntad y de la conciencia, porque están estructuralmente determinadas. En este sentido "lo social" expresa la suma de relaciones en la que están insertos los agentes sociales» (Cragnolino, 2011: 5).

Asimismo, este artículo constituye un intento por superar ciertas miradas dicotómicas que parten de identidades preestablecidas $\mathrm{y}$, aparentemente, estáticas y contradictorias: los chacareros y los empresarios, los pequeños productores y los pooles de siembra, los ganadores y los perdedores, los trabajadores rurales y los contratistas. Pensamiento dicotómico que torna difícil reflexionar acerca de los modos en los cuales los espacios sociales rurales han ido adquiriendo algunas de las características de su configuración actual.

6. Si bien la movilidad espacial de la población no es un objeto de investigación novedoso, resulta ineludible mencionar aquí la influencia del llamado «giro de la movilidad» (mobility turn) que se inaugura en las postrimerías de la década de 1990 y que se expresa en las publicaciones de Urry (2000), entre otros, dando un nuevo impulso a las líneas de investigación sobre movilidad espacial de la población. En ese marco, la(s) movilidad(es) espacial(es) son concebidas como lentes que permiten indagar las dinámicas sociales rurales y urbanas.

7. Cabe señalar que en el marco de la investigación doctoral que dio lugar a este trabajo no partimos de un conocimiento a priori sino que analizamos procesos sociales, económicos, culturales y políticos que fueron mencionados, sugeridos o descritos a lo largo de las entrevistas y observaciones realizadas durante el trabajo de campo. En este sentido, trabajamos con un enfoque metodológico ecléctico que recuperó aspectos centrales del enfoque etnográfico y del enfoque biográfico, de la entrevista en tanto género discursivo y de la perspectiva histórica, y que supuso la construcción de un corpus amplio y diverso. 
Por otra parte, también nos parece fundamental dar cuenta de algunas de estas «nuevas dinámicas» en un espacio concreto, en un territorio. Es decir, hacer pie para intentar construir un conocimiento cimentado en «la realidad» (Zemelman, 2002). Por ello, en este trabajo el análisis de algunos de los principales procesos que suponen las reconfiguraciones materiales, políticas, sociales, culturales y simbólicas de los espacios rurales en la región pampeana bonaerense, es realizado en torno a un espacio-tiempo singular, el partido de San Andrés de Giles (ubicado al noroeste de dicha provincia) entre los años 2007 y 2013. La elección del recorte temporal responde a la información provista por las y los entrevistados quienes han señalado que es, precisamente, en torno al año 2007 que comienzan a percibirse grandes transformaciones en la experiencia de lo rural en el contexto ya señalado, momento histórico que coincide con ciertos hechos económicos internacionales de relevancia que son de público conocimiento. La circunscripción espacial, en cambio, forma parte de una búsqueda por identificar y analizar los síntomas de ciertas transformaciones recientes, tomando como punto de partida el complejo entramado de las relaciones sociales que se entretejen en un distrito en el cual el carácter rural todavía es señalado como una de sus principales características.

La elección de la Provincia de Buenos Aires, primero, y del distrito de San Andrés de Giles, después, se encuentra vinculada al rol de importancia que dicha provincia ha desempeñado al interior de la región pampeana desde sus orígenes y también a nuestros lazos previos con el ámbito rural. Por otra parte, cabe señalar que el caso de San Andrés de Giles ${ }^{8}$ representa un interés particular, ya que una de sus principales actividades agropecuarias, la producción tambera, ha sido profundamente afectada por uno de los fenómenos clave de las transformaciones recientes: la expansión del monocultivo de soja trans-

8. Ubicado en el noreste de la provincia de Buenos Aires y al noroeste del Área Metropolitana de Buenos Aires (105km de la Capital Federal), el partido de San Andrés de Giles, según los datos censales de 2001, tenía una población rural equivalente al 33\%. El 11\% residían en las 6 aglomeraciones rurales del partido. En este sentido, en términos intercensales (1991-2001) se observaba un incremento del 14\% de la población total del partido, mientras que la población rural aglomerada había crecido un $25 \%$ y la población urbana un $23 \%$. En términos relativos, la población del partido se hizo levemente menos rural, al descender del 38 al 33\%. Nos encontramos, entonces, ante una proporción de ruralidad superior a los promedios provincial y nacional, aunque experimentando tendencias orientadas a incrementos en la localización en pueblos (Tsakoumagkos, Giordano Buiani y González Maraschio, 2010; HENDEL, 2015). 
génica. Desde mediados de la década de 1990, la producción láctea ha sido fuertemente desplazada por dicho monocultivo dando lugar a un proceso de concentración productiva, desplazamiento de pequeños productores, éxodo de trabajadores rurales y un fuerte impacto sobre la forma de vida rural. En menos de 15 años, la cantidad de tambos en la zona ha descendido de 60 establecimientos a sólo 11 y las explotaciones de menos de 200 hectáreas, de 327 a 136 (CNA 2002; Hendel, 2009). Por otra parte, en esta región, a la expansión del monocultivo de soja y el consecuente despoblamiento rural se ha dado un proceso paralelo de construcción de «casas de fin de semana» y «clubes de chacra», que ya hemos analizado en otros trabajos (Hendel, 2014; 2015).

Numerosos autores coinciden en señalar que las cuestiones agropecuarias pampeanas de carácter estructural pasan, actualmente, por la creciente apropiación privada (monopólica transnacional) de las tecnologías claves, la consolidación de formas novedosas de organización de las unidades de gran tamaño, la orientación productiva especializada en cultivos graníferos (especialmente, la soja), los efectos del desarrollo de los biocombustibles, y la intensificación de las actividades ganaderas y tamberas, entre otros (Tsakoumagkos, et al, 2010; Flood, 2005; Gras y Hernández, 2009; Teubal, et al, 2009). Siguiendo los análisis realizados por Pedro Tsakoumagkos, Alicia Giordano Buiani y Fernanda González Maraschio (2010), parecería conveniente mantener la idea de una continuidad que atraviesa las diferentes etapas de desarrollo de la actividad agropecuaria pampeana. Sin embargo, en el marco de esa continuidad, consideramos necesario subrayar la heterogeneidad de los sujetos agropecuarios que integran los procesos productivos pampeanos y la flexibilidad con la que algunos de dichos sujetos pueden articularse:

[...] una mera enunciación de los tipos de productores agropecuarios pampeanos existentes, es ilustrativa al respecto: terratenientes extensivos, terratenientes capitalistas, terratenientes medianos y grandes articulados con productores familiares, productores familiares exclusivos o pluriactivos, pequeños propietarios, familiares contratistas, contratistas empresariales con o sin tierra, e incluso, figuras transitorias que articulan a otros sujetos agrarios. (Tsakoumagkos, et al, 2010: 3) 
Parte de esta complejidad de los actores sociales rurales se verá expresada en los próximos apartados, al reflexionar sobre algunas de las transformaciones y configuraciones actuales de los espacios sociales rurales en la región pampeana bonaerense de la Argentina y, más específicamente, en el partido de San Andrés de Giles.

Este artículo es el producto de siete años de trabajo de campo, a lo largo de los cuales construimos un enfoque metodológico que respondió a las necesidades de la propia investigación doctoral y se nutrió del enfoque etnográfico e histórico (Rockwell, 2009) y la perspectiva biográfica (Bertaux, 2005; Arfuch, 2002). El trabajo de campo consistió en viajes periódicos en los cuales llevamos a cabo entrevistas informales, entrevistas formales registradas digitalmente y observaciones en las cuales pudimos acompañar diversas situaciones escolares y comunitarias con vistas a «documentar lo no documentado» (Rockwell, 2009). Además, realizamos un intenso trabajo de archivo en la biblioteca local y en otros repositorios y analizamos fuentes estadísticas, documentales y periodísticas.

\section{Los espacios sociales rurales en la región pampeana bonaerense: movilidades, «nuevas ruralidades» y des/arraigo}

Los 90 fue ahí, donde estábamos acá haciendo pie y nos caímos. Apareció plata dulce, la famosa fiesta menemista, digamos. Y yo creo que eso hizo perder todo, vos no tenías un espejo donde mirarte si mirabas para Buenos Aires. Entonces era todo un viva la pepa y acá pasó lo mismo. Y ahí se perdió, si se venía perdiendo, ahí fue donde hizo el click, chau se perdió todo. Sacaron trenes y desaparecieron todas las localidades rurales, todas. Este, ¿la gente qué hace? Se viene al pueblo. Las rutas sobrecargadas de camiones. Pero el tren, yo creo que la sacada del tren fue una cosa terrible, aislaste a toda la gente. Nosotros estamos hablando de gente que tiene 20,30, 20 kilómetros de tierra, ¿y la gente que tiene 80, 90 si vos te vas para otros lados? (San Andrés de Giles, 2013) 
En los últimos 20 años la concentración de la tierra ha agravado las profundas desigualdades sociales en el ámbito rural pampeano9 ${ }^{9}$ Las políticas neoliberales implementadas durante la década de 1990 tuvieron como consecuencia la expulsión de más de 300.000 familias campesinas y productores familiares, agudizando el éxodo rural hacia pueblos, ciudades y hacia algunos de los barrios más pobres de las grandes ciudades ${ }^{10}$. Es en este sentido que consideramos pertinente el uso de la noción de «doble exclusión» para describir la situación que han experimentado una gran cantidad de pobladores rurales durante las dos últimas décadas: en primer lugar, un éxodo del campo hacia la ciudad y, en segundo lugar, una exclusión hacia los barrios más pobres de las ciudades (Hendel, 2014).

Si la obtención de una mayor ganancia constituye uno de los aspectos clave del modo de producción capitalista en el cual vivimos, el valor de la tierra es aquel que configura y reconfigura la producción social de los espacios sociales rurales y urbanos ${ }^{11}$. La gran mayoría de los dueños de la tierra o de los medios de producción ya no viven en el campo, pero tampoco dejan que los demás vivan allí. Las nuevas maquinarias y tecnologías que prescinden, cada vez en mayor medida, de los trabajadores y operarios han permitido a sus dueños convertir al ámbito rural en un «desierto productivo» mientras ellos se construyen fastuosas casas en nuevos y lujosos barrios privados. Por otra parte, un porcentaje importante de empresarios y profesionales que viven en los grandes centros urbanos y poseen ingresos elevados llevan a cabo una suerte de «vuelta al campo» que pretende reconstruir un pasado rural que nunca existió en forma de casas quinta de fin de semana, barrios privados y clubes de chacra que les permiten, al menos durante unos días a la semana,

9. El $82 \%$ de los productores son familias campesinas que ocupan sólo el $13 \%$ de la tierra, mientras que el $4 \%$ representado por el agronegocio se ha apropiado de casi un $65 \%$ de la tierra utilizada para la producción (MNCI, 2012). Para mayor información recomendamos visitar el sitio de internet del Movimiento Nacional Campesino Indígena: http://mnci.org.ar/

10. A lo largo de los últimos años nos hemos abocado a la reconstrucción y análisis de las trayectorias socioeducativas de jóvenes y adultos que han migrado recientemente desde zonas rurales a zonas urbanas y que residen, actualmente, en el barrio conocido popularmente como «Fuerte Apache», en el conurbano bonaerense.

11. Al decir «valor de la tierra» quisiéramos hacer alusión a la compleja noción de «renta de la tierra» $\mathrm{y}$ «renta potencial». Para un análisis exhaustivo de este último concepto en el mundo contemporáneo y, específicamente, en el ámbito urbano. Véase Smith, 2012. 
gozar de una «vida de campo» junto con la «seguridad y el confort urbanos» (Hendel 2015). A grandes rasgos, son estas dos dinámicas que acabamos de mencionar las que, en el contexto a analizar, se conjugan dando lugar a movilidades que inciden de modos diversos sobre los espacios sociales rurales pampeanos ${ }^{12}$.

A continuación analizaremos algunos de los modos en los cuales los pobladores rurales han descrito esta problemática, poniéndola en diálogo con las nociones de «arraigo» y «desarraigo», y dando cuenta de ciertos rasgos centrales de las reconfiguraciones materiales, políticas, sociales, culturales y simbólicas que han atravesado, y están atravesando, los espacios rurales en la región pampeana bonaerense y, específicamente, los espacios educativos. En este sentido, partiremos de los saberes de quienes habitan algunos de los espacios sociales rurales pampeanos bonaerenses para analizar y pensar la problemática ya mencionada. Esta decisión metodológica resulta central a una cierta concepción de la investigación social, de la producción colectiva de conocimiento y del rol a desempeñar por quien investiga (Hendel, 2018).

\subsection{Las familias nómades y sus implicancias para los espacios rurales educativos}

Porque esto es una escuela secundaria común, con toda la parte agropecuaria. Estee, pero hoy no hay hijos de pequeños productores, te lo decían ayer. Son poquitos y nada los que queda. La mayoría son hijos de [pausa] empleados. Ya sea parquero, puestero, tambero o lo que sea. Ese pibe termina de estudiar, y muy raro que, tiene que ganar muy buena plata, para poder vivir de... ¿qué va a ser? ¿empleado del padre de 1.500, 2.000 pesos? No le sirve al pibe. Y necesita seguir capacitándose y demás. (San Andrés de Giles, 2013)

- Sí, son nómades. Tienen rueditas.

- Algunos profes me decían, «no tanto».

- Y porque es depende de la visión de cada uno [...] Yo ando mucho afuera y yo te digo que son nómades. Pero no por gusto propio, sino por necesidad. Este, no es el, es un pequeño porcentaje dentro de la matrícula que nosotros tenemos.

12. Para un análisis de estas dinámicas a partir de las nociones de «producción del espacio», que Henri Lefebvre desarrollara en la década de 1970 y de «dinámicas de acumulación de capital» (Harvey, 2008), véase HENDEL, 2014. 
Pero el papá de una piba que esta acá, estaba en un tambo, se fue a otro, cambió en 3 años a 5 tambos y volvió al mismo.

- Eso implica un cambio de vivienda.

- Y conflictos familiares, implica mil cosas.

- Por eso decía, que me parecía interesante, volver a la pregunta por el arraigo. Que está puesto como un objetivo, en el proyecto, el arraigo.

- Es que, a veces a vos te toca luchar contra un monstruo que no podés. (San Andrés de Giles, 2013)

«Son nómades», «tienen rueditas», «trabajadores golondrina», «esto de moverse, de cambiar de trabajo», «familias nómades»: la movilidad atraviesa los espacios sociales rurales en el ámbito pampeano bonaerense, surcando las narraciones que de él y de sus protagonistas dan cuenta. Y es, precisamente, ese vínculo entre el movimiento y el des-arraigo, el campo y la ciudad, y su incidencia sobre los espacios sociales rurales aquello acerca de lo cual quisiéramos reflexionar en este artículo. Si bien la movilidad siempre ha estado presente en el ámbito rural pampeano ${ }^{13}$, aquello que se ha hecho presente en el marco del trabajo de campo ya mencionado es que a lo largo de las últimas décadas la movilidad ha adquirido características singulares que los mismos protagonistas de los espacios sociales rurales pampeanos nos convocan a pensar.

Desde el productor y el empleado también. Entonces hubo el desarraigo, porque vos imaginate, vos vivís acá, el chico que trabaja con vos vive en Villa Espil y tiene que ir a trabajar a Carmen de Areco, venís de acá para allá y de allá para acá. Todo eso influyó en ese chico. ¿Vos trabajás en el campo y vivís en el pueblo? Y sí. ¿Entendés? Eso fue una de las cosas. (San Andrés de Giles, 2013)

- ¿Por qué te cambiaste de escuela?

- Porque mis papás se separaron, mi mamá consiguió alquiler en Capilla y entonces nos fuimos. Después estábamos en un lugar saliendo de Capilla, pero en el pueblo, después nos cambiamos cerca del pueblo y después al otro lado. (San Andrés de Giles, 2013)

13. Basta mencionar, a modo ilustrativo, el nomadismo de ciertas comunidades indígenas y el desarraigo forzoso de otras, el vagabundeo de los gauchos y el gran éxodo rural-urbano de los años sesenta del siglo pasado. 
«[...] venís de acá para allá y de allá para acá», afirma un veterinario local, dando cuenta de uno de los modos que adopta la movilidad en la región pampeana bonaerense. Movimientos en los cuales el campo y el pueblo emergen como sus dos polos principales. Espacios divergentes donde se desarrolla, por un lado, la cotidianeidad, la vida familiar y, por otro, la actividad laboral. Dos dimensiones que la pequeña producción familiar aunaba dando lugar a una cierta forma de concebir el vínculo con la tierra y que entra en crisis de la mano del desarraigo, de la pérdida de su medio de vida y de una cierta posición en las relaciones de fuerza locales. Los pequeños productores rurales devenidos empleados emergen, así, como uno de los sujetos sociales que encarnan algunas de las transformaciones sufridas por los espacios sociales rurales contemporáneos. En los espacios rurales escolares, estos cambios se expresan con ciertas especificidades, que en el caso de los CEPT, ponen en cuestión algunos de los principios y objetivos históricos de su proyecto. Por ejemplo:

Hoy los chicos no tienen ni idea por ahí, hasta no conocen a sus abuelos. Esa relación de familia se desvinculó mucho, mucho. Y como los abuelos se fueron a vivir al pueblo, se perdió ese contacto o esa relación. Es el tiempo, también, antes los chicos tenían más tiempo de estar con la familia y la familia vivían todas más unidas y les contaban esto, qué es lo que hacía la familia, en qué trabajaban. Porque no había tanta televisión, no había tanta computadora, hoy los chicos no le dan bolilla a esto sino buscan en los jueguitos, en la computadora, piensan en otra cosa. Que es lo que nosotros tratamos de hacer desde el plan de búsqueda, tratar de meternos en la familia y que los chicos investiguen, para ver qué hacían, todas estas cosas, la cultura que teníamos antes en el campo se fue perdiendo mucho (San Andrés de Giles, 2013).

Ya hoy los que son pequeñas, pequeños productores quedan muy pocos y toda la matrícula que tenemos nosotros acá son hijos de empleados rurales. Y muchas veces son hijos de empleados rurales, que lo único que les dejan tener es una huerta de dos por dos a todo trapo, sino muchas veces no les dejan tener animales, no les dejan tener, no les dejan tener gallinas, no les dejan tener pollos, no les dejan tener vacas, no les dejan nada, animal casi nadie les deja tener. Les dejan tener la huerta o poner algún frutal y hasta ahí. Y, generalmente los ponen como caseros, la gente trabaja de casero para cuidar, para cuidar el parque y la casa del fin de semana de los dueños, de los patrones. (San Andrés de Giles, 2013) 
Como se percibe en los testimonios de los docentes y directivos que narran las características de los espacios sociales rurales domésticos y escolares, una de las tensiones que atraviesa a aquellos que «ya estaban en el ámbito rural» es la que se plantea entre la concepción de «lo rural» como un espacio productivo y aquella que concibe a «lo rural» como un lugar de ocio o esparcimiento. En el caso del pasaje recién citado, esta tensión se ve agravada por la imposibilidad de los alumnos del CEPT de llevar a cabo huertas familiares y la cría de animales allí donde viven. Pero, como veremos a continuación, no se trata de una tensión que se exprese de forma exclusiva en las escuelas técnicas rurales.

2.2. El espacio social rural como lugar de disputa: esparcimiento vs. producción familiar

[...] Y de última, en este último, no sé, 5, 10 años para atrás en San Andrés de Giles, se instaló la modalidad de comprar campitos de 20 hectáreas, 10 hectáreas, 5, como chacras, de gente que viene los fines de semana para, pero como que el campo, el campo es, para mí el campo es la parte de producción y, para mí, también tiene su aspecto que es como naturaleza, esparcimiento pero, bueno, es como, es como si fuera que yo voy, no sé, a la Plaza de Mayo, a la Plaza de Mayo, en Buenos Aires y miro el monumento y para los políticos es un espacio de acción y yo voy y miro otra cosa en el mismo lugar. En el campo yo miro que esto es un lugar de producción y que uno como que cuida de no romper un camino, y a lo mejor viene alguien de afuera, de los que vienen los fines de semana y hay barro y salen con la $4 \mathrm{x} 4$, a ver cómo anda y rompen el camino, sin necesidad y alguien tiene que arreglarlo, como enfoque. (San Andrés de Giles, 2013)

En este caso resulta interesante, y paradójico, que quien afirma la importancia de cuidar el campo y de seguir concibiéndolo como un espacio eminentemente productivo sea uno de los principales empresarios rurales de la zona. Es decir, uno de aquellos que «levantaron taperas y cultivaron hasta en las banquinas» (Hendel, 2015). Sin embargo, para él también la experiencia de lo rural entendida como esparcimiento plantea problemas y tensiones, claro está que de distinto tipo a las que les plantea a la comunidad del CEPT. En la misma línea argumentativa otro poblador, que es historiador y presidente de la Cooperativa de Luz de Azcuénaga, realiza el siguiente análisis: 
Y, bueno, la importancia de Azcuénaga en cuanto a habitantes más o menos siempre tuvo la misma cantidad entre 200 y 400 habitantes, más de eso no ha tenido a lo largo de la historia. Pero la diferencia enorme está en la población rural, los alrededores de Azcuénaga llegaron en un momento a tener unos 2000 habitantes, te digo que hay una guía comercial de la provincia de Buenos Aires del año 1939, eh, donde figuran todos los pueblos, bueno, Azcuénaga figura con una población estimada en los alrededores de más de 2000 habitantes y toda esa gente venía a comprar al pueblo, por eso Azcuénaga antes tenía tantos comercios que ahora no los tiene, había varios almacenes, varias herrerías, carpinterías que, que hoy no se conciben. Está bien que las costumbres han cambiado, pero en gran parte era por la población rural que hoy día se ha ido a las ciudades, su gran mayoría, el campo está despoblado. Por lo general los campos los han comprado personas de Buenos Aires, que mantienen un puestero o una persona, un cuidador, este, y no los habitan esos campos, solamente para fin de semana, ese es otro cambio también que ha habido en las costumbres. (Azcuénaga, 2009)

Resulta sugerente la idea de «habitar» planteada por este poblador, quien afirma que el uso temporario de los campos durante los fines de semana no puede ser considerado como una forma de «habitarlos», entendiendo por esto último el desarrollo de la vida y de las actividades productivas tradicionales de ese espacio. Por otra parte, resulta imposible no detenernos en el doble desplazamiento analizado en este testimonio, que vincula algunos aspectos clave de aquello que estamos tratando de pensar: por un lado, el desplazamiento de «la población rural que hoy día se ha ido a las ciudades»y, por otro, el de «las personas de Buenos Aires» que han comprado campos y solamente los usan los fines de semana. Un doble desplazamiento que permite entrever dos aspectos que caracterizan a algunos espacios sociales rurales en el ámbito pampeano bonaerense: la exclusión de aquellos que ya no resultan útiles, imprescindibles (y que, en la mayoría de los casos, terminan viviendo en los barrios más humildes del conurbano bonaerense o trabajando como caseros o puesteros en el ámbito rural) y, por otra parte, la aparición de nuevos actores sociales cuyo nivel adquisitivo les permite tener más de una propiedad y construirse casas de fin de semana en el ámbito rural.

Siguiendo con este análisis, los siguientes relatos dialogan de un modo enriquecedor con el análisis que venimos realizando, al asociar el desplazamiento urbano-rural a la crisis de los pueblos rurales: 
Nos ha pasado un cambio de propietarios muy importante, gente de la Capital Federal que se viene a instalar a Heavy, por ejemplo, instalando cosas nuevas, novedosas o viniendo un fin de semana a pasear. Tenemos muchas casas de gente que viene solo los fines de semana y pocos que están ahí y que, digamos, luchan por el crecimiento del pueblo. Entonces uno ve, en el correr de los años, que las actividades productivas donde no predomina la mano de obra, la falta de tren, la falta de comodidades y estos nuevos propietarios hacen que no, que los pueblos no crezcan en realidad. (San Andrés de Giles, 2013)

- El tema de esto que me decía, que los campos empiezan a ser comprados por gente de Buenos Aires.

- Eso se empezó a dar ahora en la época del gobierno de, del turco, a partir de esa época, con el uno a uno.

- En los 90.

- Sí. Que el campo empezó a andar mal y la gente tradicional de campo, que siempre vivió en el campo acá, comenzaron a venderlo. Entonces, ahora por ejemplo, ese Camino de los Ingleses que estaba todo poblado por irlandeses antes, ahora la mayoría de los campos son comprados por gente de capital. Que no se integran mucho con los pequeños pueblos así vecinos. Por lo general vienen los fines de semana nada más, y lo que quieren es estar tranquilos y que nadie los moleste. Ese es otro cambio, porque en otras épocas los dueños de estancias que venían de Buenos Aires, por lo general se, se involucraban mucho con las actividades del pueblo y colaboraban con la escuela, con el club, había sociedades de fomento, con cualquier institución se conectaban bastante ellos.

(Azcuénaga, 2009)

De todos modos, así como estos relatos asocian las transformaciones económicas, sociales y políticas recientes a la presencia de nuevos pobladores provenientes de la gran ciudad y a la crisis de los pueblos, no quisiéramos dejar de mencionar que otros relatos, muchos de los cuales han sido recogidos durante el trabajo de campo en conversaciones informales, plantean otros matices: fundamentalmente, que ese mismo modo de habitar el ámbito rural durante algunos días a la semana, sumado al turismo rural, ha colaborado con la reactivación económica de los pueblos rurales.

Por otra parte, debemos señalar que, tal como se puede observar en los siguientes relatos, algunas de «las personas de Buenos Aires», efectivamente, se mudan al ámbito rural y encaran actividades productivas de distinto tipo. 
Tales son los casos que narran a continuación una docente y una madre del CEPT N²:

- Y en mi caso no, yo llegué al campo a los 15, me fui del Gran Buenos Aires. A los 18 me fui a La Plata a estudiar, hasta los veintipico que volví. Yyyyy, y entré acá a los 25, 26. Así que no soy nacida en la zona rural.

- Y cómo es que venís a vivir acá.

- Mi familia. Cuando yo tenía $15 \mathrm{mi}$ familia decide venirse al campo. Al campo específicamente, ni siquiera al pueblo. $\mathrm{Y}$ ahí nos quedamos. De hecho yo compré ahora un lotecito en el campo.

- ¿Y sabés por qué se vinieron?

- Porque mi papá se había cansado del trabajo que tenía allá. Entonces decidió dejar aquello y compró acá y empezó con una producción de chanchos sin saber hacer nada. Y de esa forma siguió manteniendo a la familia. (San Andrés de Giles, 2012)

- Claro, porque es como que compraron campos y los de Capital vienen, o sea, hacen producciones en el campo, entonces es como que se ve más gente ahora que antes, ¿me entendés? (San Andrés de Giles, 2013)

Si a lo largo de las últimas décadas las dinámicas recientes del agro pampeano han sido pensadas y analizadas, fundamentalmente, teniendo en cuenta el carácter «excluyente» de las mismas, a partir del análisis que aquí hemos realizado quisiéramos aportar al debate actual la necesidad de pensar los espacios sociales rurales contemporáneos a partir de sus múltiples dimensiones y en la mayor complejidad posible, para así poder contribuir a la construcción de una ruralidad más justa y diversa.

\subsection{Des/arraigar: los espacios sociales rurales y una «nueva ruralidad».}

«Arraigar», del latín ad- 'a, hacia' y radicāre, «echar o criar raíces» ${ }^{14}$ (RAE) acepción que nos remite a la imagen del cultivo, de la fijación a la tierra y nos remonta a aquellos relatos que narran la relación que establecen los hijos e hijas de pequeños productores rurales devenidos caseros con la producción agropecuaria, con la tierra, con el ámbito rural. Una «nueva ruralidad» que es descrita del siguiente modo:

14. Diccionario de la Real Academia Española. Consultado en marzo de 2014. 
- [...] Acá tenés todas pequeñas porciones de tierra, te vas para el lado de Tres Lomas, para el oeste, y tenés todas porciones de tierra grande, ¿entendés? Las ruralidades son todas diferentes. Y sí, y sí hay, yo siempre digo, y a veces suena feo, hay una nueva ruralidad, que va apareciendo, que son este tema de estos pibes.

- ¿Qué sería para vos una nueva ruralidad?

- Sí. Esto de moverse, de cambiar de trabajo, de no tener posibilidades de continuar su trabajo en el medio donde viven, trabajando donde viven. Estee, oportunidades nuevas. No, los pibes no se pueden quedar adonde están, muchos, otros sí. (San Andrés de Giles, 2013)

La noción de «nueva ruralidad» aquí desarrollada por uno de los docentes del CEPT $\mathrm{N}^{\circ} 2$ se distancia de los debates académicos sobre el tema y hace alusión, por un lado, a la heterogeneidad de ruralidades («Las ruralidades son todas diferentes»), o de experiencias de lo rural que caracterizan a los espacios sociales pampeanos bonaerenses en la actualidad. Por otra parte, esa «nueva ruralidad» nos remite, también, al movimiento («esto de moverse»), a la falta de estabilidad laboral («de cambiar de trabajo»), a la necesidad de abandonar el lugar donde viven («de no tener posibilidades de continuar su trabajo en el medio donde viven, trabajando donde viven») y a la situación actual de los jóvenes («No, los pibes no se pueden quedar adonde están, muchos, otros sí»)). Es decir, al desarraigo en toda su complejidad; tanto en su dimensión espacial, signada por el movimiento, por la dificultad de echar raíces, como en su dimensión temporal, en este caso, experimentada como una imposibilidad de pensar el futuro, una dificultad para proyectarse allí donde se encuentran en la actualidad. Y de la mano de esta noción de des/ arraigo, vinculada a las raíces, emerge la idea del pueblo. Aquí podríamos parafrasear a Henri Lefebvre quien, mucho tiempo antes, al analizar el tránsito de «lo rural a lo urbano» en la Francia de las décadas de 1960 y 1970, afirmaba que «el pueblo aparece desde que hay fijación al suelo de un grupo de hombres, anteriormente nómadas o seminómadas» (Lefebvre, 1978: 26-7). Y este lazo entre el movimiento, es decir, el nomadismo, y el pueblo que ya ha sido comentado por algunos pobladores en otras citas, nos remite a una ciertas noción de desarraigo que emerge, también, como falta de apropiación de la localidad por parte de las familias que la habitan circunstancialmente, durante un periodo corto de tiempo. Y, en este sentido, la relación entre el pueblo 
y el movimiento puede ser pensada como sinónimo de crisis. Crisis de una forma de vida vinculada al trabajo con la tierra, al estar, al permanecer. Por otra parte, el término «arraigar», que los sujetos sociales rurales han traído a escena, también da cuenta de «un afecto, de una virtud, de un vicio, de un uso o de una costumbre: Hacerse muy firme». «Afecto» $\mathrm{y}$ «costumbre» son dos nociones que siguen latentes en las narraciones de quienes viven actualmente o vivieron en el ámbito rural, a pesar de la crisis que los espacios sociales rurales contemporáneos plantea con respecto a la posibilidad de arraigarse a un lugar, a un campo o a una tierra determinada.

A mí, como yo te dije, nací y me crié en el campo. Y a mí me gusta el campo, a mí me llevás a Capital y es como que me vas a matar de una angustia. Me voy, me gusta ir a pasear, ir y volver, pero no me vas a comparar, que respire aire libre, campo, con las gallinas. Ojo, a mí me encanta todo eso, atender las producciones, darles de comer, a mí me encanta, no cambiaría. Estoy acá, pero como que estoy vinculada, estoy en el campo, ¿me entendés? (San Andrés de Giles, 2013).

Me encanta el tambo. Aparte de la huerta el tambo me encanta. Es muy lindo. Cuando son tambos grandes es más lindo. Tiene una emoción. (Azcuénaga, 2009)

No sé, porque yo viví en el pueblo cuando mis papás se separaron tres años y me re aburrí, aunque podés hacer de todo allá, pero es más aburrido. A mí siempre me gustó el campo. En el campo se escuchan los pájaros nada más, allá tenés que escuchar los ruidos, las ambulancias, los bomberos, te cansa. (San Andrés de Giles, 2013)

$\mathrm{Y}$ aquello que emerge en estos discursos que hemos seleccionado es, precisamente, la investidura afectiva de una determinada experiencia del espacio rural que aparece vinculada, por un lado, al contacto con la naturaleza y la tranquilidad y, por otro, al formar parte de determinadas actividades productivas (entre las cuales, cabe señalar, que se destaca la producción lechera). Investidura que también aparece con fuerza en aquellas narraciones acerca de una experiencia rural pasada (experiencia que, en muchos casos, parecería ser idealizada). Las expresiones «me gusta», «me encanta», «me vas a matar de angustia», «a mí siempre me gustó» hacen referencia a ese afecto, a esos sentimientos que el ámbito rural sigue despertando en sus pobladores 
o ex - pobladores y, de los cuales, la literatura ha dado cuenta en numerosas ocasiones $^{15}$.

Por otra parte, la noción de «arraigo», tradicionalmente asociada a la posibilidad de «establecerse de manera permanente en un lugar, vinculándose a personas y cosas», aparece en los espacios sociales rurales vinculada a una serie de desplazamientos que se expresan en el plano discursivo, a partir del uso de los términos «acá» $\mathrm{y}$ «allá», «ir» $\mathrm{y}$ «venir», «adentro» $\mathrm{y}$ «afuera»:

Desde el productor y el empleado también. Entonces hubo el desarraigo, porque vos imaginate, vos vivís acá, el chico que trabaja con vos vive en Villa Espil y tiene que ir a trabajar a Carmen de Areco, venís de acá para allá y de allá para acá (San Andrés de Giles, 2013).

Este, eh, y mi hermano va todos los días al campo a distintas, por supuesto que el tipo de actividad que se realiza ahora no es el mismo que se realiza, se hacía antes, o el que hace hoy otra persona que tiene otra realidad (San Andrés de Giles, 2013)

- Sí, pero, bueno, es mejor moverse solo, ese es el cambio que había, que no me gustó mucho, porque allá [en Córdoba] ibas a comprar una cosa e ibas caminando o te tomabas un colectivo, para ir a otro pueblo

- Ahora estás como instalada acá

- Sí, nos pasa algo raro con M., cuando estamos allá extrañamos acá y cuando estamos acá extrañamos allá, es medio raro. (Solís, 2013)

«Se van», «vienen», «se van»... «de acá para allá y de allá para acá»... «cuando estamos allá extrañamos acá y cuando estamos acá extrañamos allá». A partir de las narraciones citadas, la experiencia contemporánea del espacio social rural pampeano parece desplegarse entre dos polos (el campo y el pueblo, «el interior» y la Provincia de Buenos Aires) o, retomando libremente el pensamiento de Gastón Bachelard, en el marco de una «geometría del ir y venir, del acá y el allá»:

Dentro y fuera constituyen una dialéctica de descuartizamiento y la geometría evidente de dicha dialéctica nos ciega en cuanto la aplicamos a terrenos metafóricos. Tiene la claridad afilada de la dialéctica del sí y del no que lo decide todo. Se hace de ella, sin que nos demos cuenta, una base de imágenes que dominan todos los pensamientos de lo positivo y de lo negativo. [...] El más acá

15. Probablemente, el trabajo más completo en este sentido haya sido el realizado por Raymond Williams en su obra «El campo y la ciudad» (2000). 
y el más allá repiten sordamente la dialéctica de lo de dentro y de lo de fuera: todo se dibuja, incluso lo infinito [...] ¿Dónde está el peso mayor del estar allí, en el estar o en el allí? (Bachelard, 2000: 185-6)

Sin embargo, esa geometría que conforma esa base de imágenes que dominan todos los pensamientos de lo positivo y de lo negativo, no es tan claramente discernible en los discursos citados. «¿Dónde está el peso mayor del estar allí, en el estar o en el allí?». No nos resulta fácil responder a esta pregunta, a excepción de la primera narración en la cual el peso está claramente ubicado en el «irse». En este sentido, coincidimos con aquello que señala Bachelard más adelante en su obra acerca de que «la dialéctica de lo de dentro y de lo de fuera se multiplica y se diversifica en innumerables matices» (Bachelard, 2000: 188). Pero aquello que queremos observar es que esa dialéctica del ir y el venir, del acá y el allá, atraviesa y marca los espacios sociales rurales haciendo referencia a esos desplazamientos y devenires que la caracterizan en la actualidad. Es en este contexto que nos parece relevante hacernos algunas preguntas: ¿Cómo son percibidos o experimentados los espacios sociales rurales en el ir y venir, en el desplazamiento? ¿A qué otras experiencias del espacio dan lugar las transformaciones rurales contemporáneas? ¿Es posible pensar nuevas formas de arraigo en este contexto signado por la movilidad? Preguntas que se mantienen abiertas y nos invitan a seguir investigando junto a quienes recorren los espacios sociales rurales pampeanos en la actualidad.

\section{Reflexiones finales: espacios rurales, afectos y movilidades}

A partir del recorrido analítico que hemos desarrollado, podemos sostener que las movilidades, en el ámbito rural pampeano bonaerense, van de la mano de la transformación de un modo de relacionarse con el espacio y el tiempo, con la tierra y con un conjunto de saberes, de prácticas y experiencia. Es decir, que la movilidad, o las movilidades, suponen ciertas redefiniciones de los espacios sociales rurales sobre las cuales resulta imperante reflexionar. En este trabajo hemos focalizado la mirada en una escuela rural de alternancia, el Centro Educativo para la Producción Total N ${ }^{\circ} 2$ de San Andrés de Giles. 
Sin embargo, las características de esta institución educativa y la diversidad de sujetos sociales entrevistados nos han brindado una mirada más compleja sobre otros espacios sociales en proceso de cambio. Por otra parte, la noción de movilidad, o de regímenes de movilidad, ha emergido a lo largo de este trabajo de la mano del concepto de «nueva ruralidad» que hace referencia al movimiento implícito en la falta de estabilidad laboral, en la necesidad de abandonar el lugar donde viven y en la imposibilidad de los jóvenes de proyectarse en ese lugar.

Por último, proponemos pensar este abordaje de la movilidad, como dimensión clave del espacio social rural pampeano bonaerense, y específicamente gilense, en conjunto con el análisis del significante «nómade». Dicho significante se ha hecho presente en una variedad de discursos, nombrando en distintos momentos históricos y con diferentes implicancias, a las comunidades indígenas de la región pampeana, a los gauchos y los vagos, más tarde (especialmente, a quienes se resistían a formar de esa mano de obra necesaria para el desarrollo de la producción agropecuaria) y, finalmente, a los pequeños productores o trabajadores rurales contemporáneos, devenidos puesteros, parqueros o caseros. En este sentido, el término «nómade», entendido como movilidad de los sujetos sociales que solían poblar la pampa bonaerense, se va constituyendo a través de los relatos en sinónimo de desarraigo, de migración al pueblo y a la ciudad, de búsqueda de mejores condiciones de empleo, de las consecuencias que han tenido las transformaciones que caracterizaron al agro pampeano durante las últimas décadas, de trabajo por contrato, de inestabilidad y de ruptura de una cierta configuración y experiencia de los espacios sociales rurales que aunaba el lugar de trabajo y el lugar de vida. En este sentido, podemos pensar que estas movilidades implícitas en el uso del término nómade dan cuenta, en cierto modo, de nuevos modos de experimentar y concebir tanto a los espacios sociales rurales como urbanos.

La compleja realidad que atraviesan los espacios sociales rurales de la región pampeana, que en este trabajo hemos propuesto pensar junto con ciertas dinámicas asociadas a la movilidad, da cuenta de procesos de des/ arraigo y desplazamiento. ¿Acaso la sugerente noción de Roland Barthes pueda servirnos de inspiración para pensar en otras formas de habitar los espacios sociales rurales? ¿Será posible desarrollar «raíces en el aire» 
mientras creamos ruralidades más justas y luchamos por una distribución más equitativa de la tierra en la región pampeana argentina?

\section{Referencias}

Arfuch, L. (2002). El espacio biográfico. Dilemas de la subjetividad contemporánea. Buenos Aires: FCE.

Bertaux, D. (2005). Los relatos de vida: perspectiva etnosociólogica. Barcelona: Bellaterra.

Cragnolino, E. (2011). «La noción de espacio social rural en el análisis de procesos de acceso a la educación de jóvenes y adultos y apropiación de la cultura escrita». En M. del C. Lorenzatti (comp.), Procesos de alfabetización y acceso a la educación básica de jóvenes y adultos (pp. 191-209). Córdoba: Vaca Narvaja Ed.

Flood, C. (2005). «Cambios en la producción pampeana en la década del '90: tecnología y contexto». En R. Benencia, C. Flood, Trayectorias y contextos. Organizaciones rurales en la Argentina de los noventa. Buenos Aires: La Colmena.

González Maraschio, F. (2008). «Nuevas dinámicas rurales en partidos del noreste bonaerense. Una aproximación desde los usos del territorio». II Jornadas Nacionales de Investigadores de las Economías Regionales. Ciudad de Tandil, Provincia de Buenos Aires.

Gorenstein, S., Napal, M. y M. Olea, (2007). «Territorios agrarios y realidades rururbanas». Revista eure, 100, 91-113.

Gras, C. y V. Hernández (coord.) (2009). La Argentina rural. De la agricultura familiar a los agronegocios. Buenos Aires: Biblos.

HARVEY, D. (2008). La condición de la posmodernidad. Investigación sobre los orígenes del cambio cultural. Buenos Aires: Amorrortu.

Hendel, V. (2009). «Sociedad, naturaleza y nuevas tecnologías. La problemática del monocultivo de soja en el partido de San Andrés de Giles». Revista Theomai. Estudios sobre Sociedad y Desarrollo. 20. $62-80$.

Hendel, V. (2009). «Transformación productiva y reorganización de las relaciones sociales en el ámbito rural del partido de San Andrés de Giles. Un estudio comparativo: 1988-2002». XXVII Congreso $A L A S$, Facultad de Ciencias Sociales, UBA, 31 de agosto al 04 de septiembre. 
Hendel, V. (2014). «¿De lo rural a lo urbano? Transformación productiva y mutación de la experiencia del espacio en la región pampeana argentina del siglo XXI». Ecología Política. Cuadernos de Debate Internacional, 47, 78-81.

Hendel, V. (2015). Tesis doctoral «Síntomas de una ausencia. Acerca de la experiencia contemporánea de lo rural en la región pampeana bonaerense. El caso de San Andrés de Giles (2007-2013)». Facultad de Ciencias Sociales, Universidad de Buenos Aires.

Hendel, V. (2016). «Desplazamientos. Un análisis de casos de migración rural/rural en el partido bonaerense de San Andrés de Giles». Jornadas: Un siglo de migraciones en la Argentina contemporánea: 1914-2014. Buenos Aires, Argentina.

Hendel, V. (2018). «Los modos de la mirada. Aportes para una epistemología crítica de la observación en la investigación social». De Prácticas y Discursos. Universidad Nacional del Nordeste Centro de Estudios Sociales. 7(9). 55-73.

Lefebvre, H. (1971). De lo rural a lo urbano. Barcelona: Edicions 62.

Movimiento Nacional Campesino Indígena (2012). Derecho al Territorio Campesino Indígena. Córdoba: MNCI.

Rockwell, E. (2009). La experiencia etnográfica. Historia y cultura en los procesos educativos. Buenos Aires: Paidós.

Sмiтн, N. (2012). La nueva frontera urbana. Madrid: Traficantes de Sueños.

SoJA, E. (2008). Postmetrópolis. Estudios críticos sobre las ciudades y las regiones. Madrid: Traficantes de Sueños.

Teubal, M., Domínguez, D., Sabatino, P. (2005). «Transformaciones agrarias en la Argentina. Agricultura industrial y sistema alimentario». En N. Giarraca y M. Teubal (comp.), El campo argentino en la encrucijada. Estrategias y resistencia sociales, ecos en la ciudad. Buenos Aires: Alianza.

Tsakoumagkos, P.; Giordano Buiani, A. Y González Maraschio, F. (2010). «Productores familiares, agriculturización y pluriactividad en el noreste bonaerense (Argentina) ». VIII Congreso Latinoamericano de Sociología Rural (ALASRU), Porto de Galinhas, Pernambuco, Brasil.

UrRY, J. (2000). «Mobile Sociology». The British Journal of Sociology. 51(1), 185-203.

Williams, R. (2001). El campo y la ciudad. Buenos Aires: Paidós.

Zemelman, H. (2002). El conocimiento como desafio posible. México: Hidalgo/UPN. 